\title{
AOR
}

Selected Papers of \#AoIR2020:

The $21^{\text {st }}$ Annual Conference of the

Association of Internet Researchers

Virtual Event / 27-31 October 2020

\section{FACEBOOK: FROM PERSONAL MEDIUM TO MASS MEDIUM - AND BACK AGAIN? \\ - THE USE OF FACEBOOK ACROSS AGE GROUPS 2015-19}

\author{
Jakob Linaa Jensen, Ph.D. Research Director of Social Media, Danish School of Media \\ and Journalism.
}

\section{Introduction}

Social media, most prominently Facebook, has come to play an important role in everyday life of many people throughout the globe. When Mark Zuckerberg launched his social network site, The Facebook, at Harvard University in 2004 few, if any, could expect, that 15 years later in 2019 it would have 2,5 billion users and 70 billion dollars revenue, of which almost everything comes from advertising. The latter shows that Facebook is far beyond the original social network site, it is a major player in the platform economy and in terms of advertising, readers and interaction, in many countries it is more important than traditional mass media.

\section{Personal media vs mass media}

One might claim that Facebook is in fact a mass medium. Lüders (2008) operates with a distinction between personal media and mass media based on two axes: an institutional and interactional. By its revenue and position in the globalized media system, I will argue that Facebook institutionally long ago has become a mass medium. In regard to interaction, I will argue that Facebook is both; it is personal because of its interactional nature. But it is also a mass medium as it has been increasingly used by politicians, corporations and organization to communicate content to large and dispersed audiences. Facebook is simply, like TV and (to a decreasing degree) newspapers an important place to be, in election campaigns, in crisis situations and in everyday life.

Despite Facebook's enormous role for years there have been rumors about its decline. Especially, it has been claimed that the number of young users decreases dramatically (see for instance The Guardian, 2008). Such predictions have been hard to show in

Linaa Jensen, J. (2020, October). Facebook: From Personal Medium to Mass Medium - And Back Again? Paper presented at AolR 2020: The 21 $1^{\text {th }}$ Annual Conference of the Association of Internet Researchers. Virtual Event: AolR. Retrieved from http://spir.aoir.org. 
academic research and although the youngsters might use less time on the open parts of Facebook and rather prefer Instagram, Snapchat, TikTok etc. it seems as if they have just switched to the personalized features of Facebook like Messenger and private groups. They don't want to openly show themselves and discuss where their teachers and grandparents are! On the other hand, Facebook seems to be more popular than ever among the grown-ups. New research from Denmark shows that for those aged 40 to 59, Facebook is seen as the most important gateway to news and information from organizations, local government etc., indicating that it is widely regarded as a mass medium (Linaa Jensen et al., 2019).

\section{Research questions and method}

It is interesting to investigate how different age groups perceive Facebook as a personal medium and a mass medium, respectively. It is even more interesting to investigate whether we can find a trajectory over time. As Denmark for long has been one of the countries with relatively most Facebook users and as Facebook plays an important role in everyday life and the public debate, data from Denmark might give good indications of Facebook's development in general.

This paper is based on five consecutive surveys among Danish Internet users, in 2015, 2016, 2017, 2018 and 2019 ( $\mathrm{N}$ between 1200 and 1500 each year). I focus on the use of different parts of Facebook across age groups; the personalized uses like Messenger, private groups and intimate communication, versus "mass media use" like reading news, organizational and political information and taking part in nationwide debates. I also investigate different age groups' attitudes towards Facebook and whether they see it as a personal or a mass medium.

\section{Analysis and findings}

First and foremost, I find notable differences across age groups. I also find that the differences are increasing over the years. In 2015 there were not significant differences in Facebook use across age groups. In 2019 a vast majority of the youngest, aged 1830 , used Facebook dominantly as a personalized medium, highlighting Messenger and private groups as their preferred ways of communication and interaction. The older generations have a much more diversified use, treating Facebook as a personal as well as a mass medium. The group aged 40 to 59 are those who mostly use Facebook as a mass medium, indicating that news reading and filtering is an important affordance of Facebook. The oldest generation, however, like the young ones, see Facebook primarily as a personal medium, using it for keeping in touch with family, especially grandkids. They still prefer to attend to news through traditional mass media like TV and newspapers.

Data also confirms another suspicion that has been found in similar research. The vast majority of Facebook users are only "lurkers" (Preece. et al., 2004), only reading, rather than posting or participating themselves. That also explains why suspicions that Facebook is in decline might be wrong. People still read, but they don't show, explaining why activity seems to decrease. 
In general, I notice a certain Facebook fatigue. Although the number of users is larger than ever, most age groups report that they spend less time on Facebook in 2019 than in 2015. The dispersion of time consumption also increases. The most eager users spend as much (or more) time than ever, whereas the number of casual users, dropping by now and then, is on the rise.

There might be many explanations behind the figures. For the young, grown up with digital media, we can see a very dedicated and conscious navigation between different media platforms, based on a logic of appropriateness and a high level of uses and gratifications (Katz et al., 1973). For the rest, the increasing differences and intensities of use might be explained by bad press coverage of Facebook and other social media recent years in the wake of the Cambridge Analytica scandal and other breaches of privacy and data protection.

In sum, Facebook does not seem to be going down a slippery slope, yet. The number of users is as high as ever, but they are increasingly more conscious and aware of the fallacies of social media. The grown-ups mainly see Facebook as a tool to navigate the news stream and keeping in touch, the younger primarily use it for more personalized and intimate communication. These are important lessons for social media strategists, as well as for researchers framing the questions for future research.

\section{References}

The Guardian (2008). https://www.theguardian.com/technology/2018/jun/01/facebookteens-leaving-instagram-snapchat-study-user-numbers).

Katz, E., Blumler, J. G., \& Gurevitch, M. (1973). Uses and gratifications research. The public opinion quarterly, 37(4), 509-523.

Lüders, M. (2008). Conceptualizing personal media. New media \& society, 10(5), 683702.

Linaa Jensen, J., R. Buch, J.D. Johansen, P.T. Madsen \& F. Svith (2019). Report on media development in Denmark 2019: Active, overwhelmed, diverted or addicted? Copenhagen: Danish Ministry of Culture.

Preece, J., Nonnecke, B., \& Andrews, D. (2004). The top five reasons for lurking: improving community experiences for everyone. Computers in human behavior, 20(2), 201-223. 
